\title{
What motivates people to teach, and why do they leave? Accountability, performativity and teacher retention.
}

\author{
Jane Perryman \\ Institute of Education, University College London \\ Graham Calvert \\ Institute of Education, University College London
}

Corresponding Author

Jane Perryman, UCL Institute of Education, 20 Bedford Way, London WC1H OAL, j.perryman@ucl.ac.uk, 02076126577

\section{What motivates people to teach, and why do they leave? Accountability, performativity and teacher retention.}

A longstanding problem in the teacher workforce, internationally and in the UK, is the continuing and substantial numbers of qualified teachers who leave the profession within five years (Allen et al 2017, Sims and Allen 2018, House of Commons Education Committee 2017, Burghes et al 2009, Lynch et al 2016, Lightfoot 2016). This paper uses data collected from a survey to the last five years of teacher education graduates of UCL Institute of Education (IOE) in London, to explore what originally motivated them to teach, and the reasons why they have left, or may consider leaving in the future. As most research in teacher retention occurs at the exit stage, the utility and originality of the approach lies in considering why respondents initially became teachers; and asking people who have remained in teaching what may eventually cause them to leave. The strength of this project and this paper lies not only in the broader sample of those who had stayed in teaching as well as left, but also in the analysis that can be done on peoples' motivations to become teachers, and their pre-course thoughts about the perceived challenges ahead. We discovered that despite claiming to be aware of the challenges of workload before entering teaching, workload was the most frequently cited reason for having left, or for leaving in the future. The data spoke to a discourse of disappointment, the reality of teaching being worse than expected, and the nature (rather than the quantity) of the workload, linked to notions of performativity and accountability, being a crucial factor. This paper draws on a substantial new source of data and explores reasons for leaving in the context of reported initial motivation of individuals who have left teaching, individuals who are planning to leave and individuals who are planning to stay in teaching. This research will be significant to academics in informing the discourse around teacher retention, to leadership teams in schools who are responsible for setting up support mechanisms to retain staff, and to policy makers in this crucial area.

The data we collected, from a survey of the IOE Initial Teacher Education (ITE) alumni database, numbering around 3,500, showed that workload and work/life balance were the top two reasons cited for leaving, irrespective of hopes and fears coming in. Our main 
findings were that teachers entered the profession because they wanted to work with young people and 'make a difference', but once they started in teaching, other factors, the reality of daily life as a teacher, dulled their enthusiasm, as exemplified in this typical quotation from our sample, a social science teacher in a secondary school who after 4 years moved into Special Education;

I feel I came into teaching for all the right reasons (passionate about my subject, a strong work ethic and a love of watching students learn) but am leaving for all the wrong reasons (workload, specification changes, not being able to have a life and too many classes / students). It makes me really sad that I had to leave a subject that has a shortage of teachers, but I could not do the things I want to do in my life like have children and continue being a mainstream secondary school teacher.

The results of the research are interesting as they reveal a contrast between the teachers' reasons for entering and leaving the profession. The reasons cited for becoming a teacher seem largely altruistic - wanting to 'make a difference', wanting to work with young people and love of their subject. The reasons for leaving or for thinking of leaving were workload and work/life balance as well as target driven culture and government initiatives. These reasons for leaving seem to reflect a discourse of disappointment about the reality of teaching, the wider context, and the accountability/performativity culture in which teachers work.

\section{Policy Context}

Teacher attrition constitutes a problem for governments internationally, in that it represents a highly inefficient use of resources, and a problem for schools and school students, whose interests, it can be assumed, are not best served by an unstable, constantly changing teaching force. Teacher attrition is an international problem. In the USA, Ingersoll (2002) found that $46 \%$ of new teachers left their job in the first five years of service. In Australia, Stoel et al (2002) noted an 18\% drop-out rate in women aged 25 to 29 years (they did not have the data for men). Karsentil and Collin (2013) estimate a teacher turnover rate of somewhere between 3 and $30 \%$ in the first five years of service in Canada. In Sweden, Lindqvist et al (2014) reported that $16 \%$ of teacher graduates were not working as teachers in 2010. Den Brok et al (2017) estimate an attrition rate of $15 \%$ in Sweden. In the UK, a report to the House of Commons Education Committee (2017:2) concluded 'while recruiting sufficient new teachers is, of course, necessary, the Government should place greater emphasis on improving teacher retention. Not only is this a more cost-effective way to tackle some of the issues, but more teachers staying in the profession for longer would strengthen the pool of leadership positions'.

Teacher retention is perceived to be vital because, as Cater summarises:

There is no profession more important than teaching. Life chances are created and futures mapped, particularly for those from less-advantaged backgrounds. Economic success... depends on a highly-motivated and well-educated workforce...The challenges are manifest and growing, and require all parties to work together constructively to secure teacher supply, teacher retention and teacher development as demands on the profession increase further (Cater 2017: 49). 
Although teacher retention is in international issue, it is particularly problematic in England. In 2009 a report by the think-tank Politea (Burghes et al, 2009) claimed that England loses a high proportion of its teachers at the start of their careers and this is exacerbated by high attrition rates. The problem appears to be growing. A report to the House of Commons (HOC 2017: 8) stated that according to The National Audit Office: 'Between 2011 and 2014, the number of teachers leaving rose by $11 \%$, with schools recruiting more teachers as a result...data show that of teachers newly qualified over a 10 -year period, approximately $12 \%$ left state-funded schools within 1 year of joining while $28 \%$ had left within 5 years'. Lynch et al (2016: 2) report that the 'proportion of teachers considering leaving has increased significantly in the last year, from 17 to 23 per cent - retention pressures are growing'. A Guardian Survey of 4450 teachers conducted in 2016 concluded that ' $43 \%$ of the state school teachers polled said they were planning to leave the profession in the next five years' (Lightfoot 2016). Marsh (2015) reported that according to a recent Association of Teachers and Lecturers (ATL) survey of its trainee and newly qualified teacher members 'more than $54 \%$ said that they did not think they'd be teaching in 10 years' time and almost a quarter imagined they'd move on in half that time'. This is in contrast to medical doctors, very few of whom intend to leave within a 25-year period despite being considered to be comparative in terms of the vocational nature of the career path (Surman et al, 2017, Goldacer et al, 2013).

Recently, in the Guardian, Savage (2017) reported that 'analysis of official figures shows that more than 27,500 teachers who trained between 2011 and 2015 had already left the job by last year. It means that just over $23 \%$ of about 117,000 teachers who qualified over the period have left'. He argued that this prompted concerns about workload, salaries and accountability pressures.

This paper will argue that these accountability pressures and the performativity culture in education is a major factor in teachers wanting to leave the profession. This is evidenced by what is commonly referred to as 'box-ticking', as teachers' work is increasingly directed towards assessment, exams, progress measures and preparation for review and inspection, and away from the more individualistic and creative aspects of the job. Performativity is a disciplinary technology that uses judgements and comparisons against what is seen as efficient as a means of control, and a culture of performativity leads to performances that measure efficiency (Ball 2003, Perryman 2009). Performativity is intrinsically linked to the emergence of the power of the evaluative state, accountability in education policy and transparency to the public gaze. In the performative accountability culture of education in the twenty-first century, efficiency is seen as 'a good thing' irrespective of the cost to people intensification, loss of autonomy, monitoring and appraisal, limited participation in decisionmaking and lack of personal development are not considered. Thus, teaching and learning are determined in accordance with learning outcomes and objectives. The teacher becomes just another learning resource, a facilitator, where teaching is theorised as the application of fixed recipes and the variety of good practice can be suppressed.

Performativity in education can lead to a sense of deprofessionalisation as teachers can feel that they are performing in order to demonstrate their competence. Tomlinson (2001: 36) maintains that teachers have become 'a technical workforce to be managed and controlled rather than a profession to be respected'. 
Keddie (2017: 1246) reports that

\section{[performativity] sets itself against traditional professionalism in its alignment with the methods, cultures and systems of the private sector. The language of business and enterprise animates this education landscape. Schools are driven by incentives of performance, economic efficiency, productivity and value-adding.}

Since the 1988 Education Reform Act, the work of teachers in England has been increasingly regulated, with the introduction of the National Curriculum, high-stakes testing and league tables, leading to a low trust regime of increased accountability in education. Schools are increasingly preoccupied with policies of achievement, particularly examination results. This has led schools to adopt a results-driven approach, with a plethora of strategies aimed at improving results. Ball (2008) argues that educational change since the 1988 Reform Act has had a 'ratchet effect' on change, bringing small incremental, cumulative moves over time which have fundamentally changed taken for granted practices. 'Each move makes the next thinkable, feasible and acceptable' (Ball 2008: 97).

This is not limited to the UK. In a study of teachers' reactions to change across nine countries, Poppleton and Williamson (2004:308) found that teachers in Australia, South Africa, Canada and England reported the greatest negative impact on their work lives, explaining 'these were all countries that were experiencing government initiated and tightly controlled reform'. By analyzing data from the Schools and Staffing Survey and the Teacher Followup Survey, Ingersoll et al (2016: 44) found strong evidence that 'accountability made teacher retention more difficult in low-performing schools; schools whose students scored low on high-stakes assessments had higher teacher turnover than those that scored higher; and schools that received sanctions because of their low performance had even higher turnover'. Lightfoot (2016) reported that 'the biggest generator of workload, say teachers, is constant change caused by government policy. The expansion of the amount of data teachers must collect and record for each pupil comes second, followed by the unfair pressure of being judged against unrealistic targets for pupil progress based on national data'. Breslin (2002) argues that teachers have been subject to routinisation, marketisation and casualisation in an environment characterised by increased surveillance. He argues that teachers need to rethink their role and abandon their commitment to the subject, which he says deskills them. It is into the arena of accountability that new teachers arrive, full of idealism, and commitment, ready to develop a socio-political consciousness in those with whom they work. Interviewing would-be trainee teachers for a position on an ITE course, we are often struck by their sheer enthusiasm for teaching their subject and their belief that as teachers they really can make a difference to pupils' lives. What happens to this?

Williams (2017) suggests;

with the vast majority putting in endless hours to achieve ever-harder targets, there is a greater certainty of burn-out than reward. The current mismatch between teachers' aspirations, interests, strengths and knowledge and the job they are expected to do is so demotivating that it leads to an annual exodus. What needs to be overturned is an accountability system that squeezes the last drop of joy out of day-to-day teaching. 
It is this mismatch between expectation and reality and the consequent discourse of disappointment that this paper will go on to explore.

\section{Method}

The focus of most surveys of teacher retention is on the immediate reasons for leaving (Cuddapah et al, 2011; Farinde et al, 2016; Makela et al, 2014). As well as why teachers left, we were interested in the links between initial motivation to become a teacher, and intentions/decisions to leave or stay. To address this, our research was designed, through the development of an online survey, to enable participants to retrospectively consider their reasons for becoming teachers, reflect on their career intentions when they commenced teacher training, and describe their path since. We exploited the opportunity to utilise the student database of London's UCL Institute of Education (IOE) as one of the largest providers of teacher training and education in the UK to recruit participants. Graduates of the IOE make up a large group of the teacher supply in London, the South East and nationally. It provided an opportunity to survey large numbers of recent graduates, and was unusual in that it surveyed those who stayed as well as those who had left.

A branching questionnaire with six sections was produced, the first four were common to all respondents, the options in the final two being dependent on whether or not participants were still in teaching. We offered different pathways depending on whether participants had already left, were thinking of leaving in the future or were intending on staying. This enabled items in each branch to be reworded - for example the 'have already left group' were asked 'the reason why I left', whereas the group who thought they might leave were asked 'I might leave because of'. Items for the questionnaire were distilled from a wide variety of existing surveys to reflect the factors identified in previous research to produce a shortened questionnaire that was accessible to respondents. We piloted the survey among staff to ensure that the items had face validity. We wanted to write a questionnaire that would achieve the maximum response rate, was not arduous for respondents and reflected the existing research on motives and reasons for leaving in teaching.

The first section consisted of a set of demographic questions (age, gender and highest level of qualification before starting teacher training), followed by twelve items designed to measure remembered reasons for becoming a teacher. Nine items in this second section were based on previously identified motivational themes (Joseph \& Green, 1986; Richardson \& Watt, 2005; Watt et al., 2012) such as 'I wanted to work with young people' or 'I had always wanted to work with young people'. The four remaining items addressed the possibility that teacher training was seen as a path to careers outside of teaching, or as a career experiment. As with all the fixed response questions, the free entry option of 'other' was given. The third section listed eight career goals, giving participants the opportunity to recall their plans before starting teacher training. To provide a more nuanced analysis of beginning teachers' expectations, participants were asked to retrospectively describe the things they thought would be most enjoyable and most challenging about being a teacher. The fourth section covered their teaching training pathway and its outcome. Participants who did not complete their teacher training were directed to modified sections five and six which omitted items relating to career intentions in teaching. The fifth section related to current employment and future career goals, and the final section explored reasons why one 
might leave if still teaching, or reasons for having left if already departed. These reasons were once again drawn from the themes in existing research (Cacha, 1981; Grayson \& Alvarez, 2008; Kyriacou, 1987) alongside exploring the possibility for those who had left that the intention had always been to leave teaching.

The questionnaire was produced using the Opinio online survey tool, initially piloted among five members of UCL/IOE staff who provided detailed feedback on wording, formatting and sequencing of items. A single email invitation was sent to the 3596 ex-trainees, across all routes (PGCE primary, secondary and post-compulsory ${ }^{1}$, School Direct funded and unfunded ${ }^{2}$ and Teach First ${ }^{3}$ ), from the last previous five years, whose details were held on the UCL/IOE ITE Alumni database, repeating the invitation via tutors and their personal contacts. Participants were given the opportunity to enter a draw for a new iPad as an incentive to complete the survey. The time taken to complete the questionnaire varied between 5 to 10 minutes. The data set was inspected and cleaned before analysis, removing those who had only completed the first section, resulting in a loss of 117 people from the initial 1317 responses, giving a total, usable sample of 1200 . As we were unable to collect information on the exact number who actually received the survey we assumed the upper end of 3596 potential respondents, giving an adjusted response rate of $33 \%$ which is in line with the expected online survey response rate (Nulty, 2008).

$27.2 \%$ identified as men and $72.8 \%$ identified as women. They ranged in age from 21 to over 51 years, the majority $(47.4 \%)$ in the age group $26-30$ years. In all, $64 \%$ came into teacher training with at least a 2:1 in their first degree, with an additional $24 \%$ having a postgraduate qualification. In terms of the age group that the participants were trained to teach, $34.3 \%$ went into Primary, $56 \%$ into Secondary and $9.3 \%$ into Post Compulsory. This was representative of the intake profile of the UCL/IOE as a whole.

Bivariate and multivariate statistical analysis was conducted using SPSS. Given the potential bias in a self-selecting sample, the low number of categories, and the exploratory nature of the analysis, binary logistic regression was chosen as being more robust and making fewer assumptions about the data (Pohar, 2004; Reed, 2014) to identify which demographic, motivational and career goal factors might discriminate between those who left before completing their teaching training, those intending to leave in ten years and those intending to stay in teaching. The open responses were uploaded into NVIVO to assist with the initial stages of organising the data. We used a word-cloud to analyse frequency and prevalence of words, combined with a detailed contextual analysis of each response, looking for items that elaborated or contradicted the statistical findings. We tested the reliability of our selection by each of us identifying quotes that were useful, blind to each other and then comparing our analysis.

The data that we use in the paper is representative across the range of our participants, both demographically and in the intention to leave or stay. We have identified quotations within the text or after the quote, feeling it useful to identify

\footnotetext{
${ }^{1}$ Post Graduate Certificate in Education - an academic qualification achieved during training covering different age ranges

2 School Direct - school based teacher training, the funded route offering a salary

3 Teach First - a two-year employment-based teacher training programme
} 
gender, age, training route, and length of time in teaching. Gender is identified by $f$ or $\mathrm{m}$ and age is expressed as a range. The training routes are explained in footnote 1.

\section{Findings and Discussion}

\section{Who Left - the statistics}

From our sample of $1200,1.5 \%$ (18) withdrew before completing their initial teacher training, $3.6 \%$ (44) withdrew after completion of their training but before starting their NQT year, and a further $1.5 \%$ (18) left during their NQT year. An additional 13\% (158) become teachers but have since left. Of this group of 158, 34\% left in their second year and $23 \%$ in their third teaching year. Overall the percentage of actual leavers in this sample was $19 \%$ within five years of starting teacher training.

The percentage of respondents from each cohort who left were; $15 \%(2011), 19 \%$ (2012), 11\% (2013), 10\% (2014) and 3\% (2015). We found no association with length of service and number of leavers/planning to leave and number planning to stay. We cannot tell when people leave as such but can infer that there is no sudden increase in attrition for example after two years

The figure of $19 \%$ is quite low in comparison to the statistics quoted above which might relate to a response bias of those having left teaching being less likely to respond to the survey. This was countered by the figures for the intention to leave which brought our potential attrition rate from teaching back up to national averages. Of those who were still in teaching (962), 153 (16\%) were planning on leaving teaching within the next 5 years, a further $225(23 \%)$ were planning on leaving within the next 10 years. From the total sample of 1200,584 (48\%) were committed to teaching representing a potential loss of $52 \%$ of trainee teachers over a 10-year period, in line with national trends. Obviously we do not have the evidence to say they will actually leave, but presenting intentions to leave which demonstrates an uncommitted workforce. There are, of course, a whole range of forces which may impact on their plans to leave which we cannot explore (such as loss of income, lack of opportunity), but these are current reported intentions, and are in line with actual leavers figures nationwide.

One of the key areas of interest at the start of the research was a comparison between the initial motives of those who intended to stay in teaching and those who had left or were intending to leave (excluding those who did not complete their teacher training). We wanted the research to interrogate the extent to which a short stay in teaching had always been the plan and rather than being pushed away from teaching as a career the leavers are pulled by more exciting opportunities, or paths for which a short-term teaching post was vital and necessary preparation. Were they pulled towards other exciting opportunities, buying into global and post-modernist discourses about transferable skills?

The sample was therefore recoded into these two groups before applying a stepwise binary logistic regression method to screen motivational, demographics and career 
intentions. We found that demographic factors such as age, gender, course taken or whether someone was in primary, secondary or tertiary education seemed to make no difference to the intention to leave. There was some correlation between those who were likely to stay and a long-term leadership career plan, and an initial motivation of 'always wanted to be a teacher'. Unsurprisingly, the intention to leave was underpinned for a significant minority who had intended to use teaching as a stepping stone to other careers. More interesting is the suggestion that the initial motivation of wanting to 'be creative' is associated with eventually wanting to leave. This aspect is supported by the qualitative data, and feeds into our notion of a discourse of disappointment.

Before discussing the reasons why people left or thought they might leave, in order to fully understand them it is useful to explore why they became teachers in the first place - what motivated them?

\section{Findings: Motivations for becoming a teacher, and rewards of being in teaching}

According to our survey (closed option multiple answer), the main reasons for becoming a teacher were:

- Wanting to 'make a difference' (69\%)

- Wanting to work with young people (64\%)

- Love of subject (50\%)

- Inspired by own teachers (38\%)

- To have an intellectual challenge (36\%)

- To be creative (35\%)

- Variety of work $(33 \%)$

We also asked open questions about what people had expected to be the rewards of teaching, and what they actually enjoyed (or had enjoyed) most about teaching. Having analysed the data as detailed above, we found that the most cited rewards of teaching (both anticipated and actual) were:

- Working with children / pastoral

- Students learning and loving the subject

- Helping students achieve

It is interesting to note at this stage the close correlation between the expected and actual rewards of teaching. In open-response answers, recollecting what they had had thought would be the most rewarding aspect, our respondents were also motivated by the thought of doing a job where they could continue to engage with their own subject 'I wanted to share my love of French' (f, 46-50, PGCE secondary, left during NQT year), and thought that teaching would provide a job with variety and an opportunity to be creative. One respondent, said 'I thought planning those 'wow' lessons would be the entirety of my profession, (f, 26-30, PGCE primary, 4 years, intends to leave), and another wrote 'I thought l'd be coming up with incredible inspiring lessons every day' (f, 31-35, PGCE 
primary, 5 years, intends to stay). These responses seem to indicate that these dreams were not realised.

Having asked our sample in an open question what rewards they anticipated, we also asked them about the positive reality of teaching. The actual rewards reported by our sample also included variety and creativity, but added relationships with colleagues and seeing children make progress.

One of our respondents wrote;

When children beg to stay in at lunch so they can continue with their learning; when children come in with extra homework, they've written you pages and pages of stories and you find the time to share those with your class; when children tell you they know that you care about them because your eyes shine when you teach them; the special thank you cards from parents or when they tell someone in SLT that you're amazing (f, 31-35, PGCE primary, 5 years, intends to stay)

Another claimed 'they give me so much happiness' (f, 26-30, Teach First primary, 3 years, intends to leave). There is much in our data about this aspect of forming relationships with children, an intrinsic sense of worth and also many mentions of fun and laughter; 'the fact that my year tens made up a football hooligan style chant to express their love of history (still not sure about that one!)' (m, 31035, PGCE secondary, 3 years, intends to stay) and 'when you make an entire class laugh and realise they trust you' (f, 31-35, PGCE secondary, 5 years, intends to stay).

For some of our respondents one of the main rewards concerned the progress they could help their students make to change their lives for the better - 'I was very proud to observe [them] growing from insecure dependent children to bright confident inspirational young adults' (f, 26-30, PGCE secondary, left after 4 years). For teachers of younger children this was expressed in terms of motivating them and providing a 'consistent figure in [their] lives' and enabling them to 'feel calm safe and secure'. Teachers of older students expressed this in terms of good exam results and students going off to college and university to read 'their' subject.

Seeing a set of excellent examination results and realising all my hard work for the year has paid off. Seeing 'lazy' students turn it round and mature into young adults. Seeing students' mindsets change as they start to put their own journeys into a wider context (f, 31-35, PGCE secondary, 2 years, intends to stay)

Helping students achieve their goals and go off to university, their delight and surprise when their hard work pays off and they do better than expected. When students come back to say thank you and that we made a difference $(\boldsymbol{f}, \mathbf{2 1 - 2 5 ,}$ PGCE secondary, 4 years, intends to stay)

These findings are similar to Sinclair's (2008) study of student teachers from two Australian universities. This found that motivations were largely intrinsic and included 'working with children, intellectual stimulation, altruism, authority and leadership, self-evaluation and personal and professional development' (Sinclair 2008: 87). Extrinsic motivations were 
'career change, job conditions, life-fit, influence of others and nature of teaching work' (ibid). Neito (2003:201) explored eight Boston teachers' perspectives over the course of a year and suggests that good teachers stay in teaching for sheer love of their students - 'understanding that teaching necessarily involves love and respect is a major theme that emerged in the work of these committed teachers.' In a study of 196 Australian trainees, Ewing and Smith (2003) found 'satisfying career', 'promote student learning', 'contribute to society' and 'help others' to be primary motivations to enter teaching.

A key addition when we asked those who were still in teaching to tell us what was enjoyable about their jobs was 'colleagues'. Not many had cited this as a reason for going into teaching, perhaps because there was an understandable lack of realization of the importance of this factor. As we will discuss later, lack of support from management and colleagues features as a reason for leaving or wanting to leave, so it is unsurprising that the reverse is true.

Also, a massive thing for me is the support of my brilliant inspiring colleagues, there is not a competitive atmosphere, just a proper team spirit and everyone pulling together for the good of our children (f, 31-35, PGCE primary, 5 years, intends to stay).

Respondents wrote about 'hard-working and dedicated colleagues' ( $\boldsymbol{f}, \mathbf{2 6 - 3 0 ,}$, Teach First secondary, 2 years, intends to leave) and described them as working 'dynamically to support each other and the students in our school' (f, 36-40, PGCE secondary, left after 4 years).

And finally, one of our respondents sums up the mix of factors that for many make teaching enjoyable

Perfect lessons, conquering the tough kid, the beauty of actually inspiring people about a book, debating with students, being surrounded by POETRY, going on school trips on sunny days, pushing myself to get better, working with inspiring people - adults and students. The thrill of standing up in front of people. When the students see something in a way that you can't. Actually, getting paid for having fun! ( $m$, PGCE secondary, 3 years, intends to leave)

The data so far, the hopes and aspirations of teaching as a job, and the sometimes moving descriptions of the joys of teaching show that for some of our sample, teaching lived up to their expectations. But for too many it did not, and led to significant numbers leaving, or planning to leave. Even the respondent intends to leave within 10 years, despite his obvious love of the job. The next section presents data to help us understand why.

\section{Perceived and actual challenges of teaching}

In an open response question, we asked what people had thought would be the most challenging thing about going into teaching. 'Pupil / student behaviour was the most predicted challenge. This was followed by fears over workload, planning and marking and time management and organization. 
Some people's worries about behaviour centred on their own personalities 'I felt I didn't have an assertive character and might struggle gaining the respect' (f, 26-30, PGCE secondary, 2 years, intends to stay), realization they needed experience and training and fears that they were too youthful. Some were concerned about the effects challenging socio-economic backgrounds would have had on the students 'I knew I was going to be working in a challenging area, so I thought dealing with parents and behaviour of the children would be challenging'(f, 26-30, Teach First primary, 2 years, intends to stay), or facing children (and their parents) with antisocial problems or rude behaviour.

It is important to note that behaviour faded as a significant challenge for those still in teaching. This is surprising as it is a commonly held belief that pupil behaviour is a major factor in teacher retention. This explains why our respondents had worries before they became teachers about classroom management, but the reality appeared to be different. If behaviour was mentioned as a challenge, then it was linked to lack of support - 'if the school does not have enough support or a system in place to manage disruptive behaviour then it takes all the pleasure out of teaching' (f, 26-30, PGCE secondary, left before completing NQT year), 'I was very badly treated there and had no support in dealing with the very challenging behaviour of the children' (f, 26-30, PGCE secondary, 5 years, intends to stay).

There are some pre-teaching fears in our data about workload pressures, 'Workload! (my mum is a teacher so I had been pre-warned!)' (f, 26-30, PGCE secondary, 3 years,

intends to stay). It is interesting to wonder why this well publicized issue was known about and recognized but did not stop people wanting to teach, yet in the end was the main reason why people left. Perhaps as one says, 'I had also seen my colleagues struggle with work- life balance / workload and knew it was a given for the job, but not the full extent' (f, 21-25, PGCE post-compulsory, NQT). Another added 'I thought it would be a challenge, but didn't realise just how challenging that was going to be' (f, 26-30, PGCE secondary, 3 years, intends to leave).

\section{Why people left}

The top reasons (closed option answer) given for leaving by those who had left were

- To improve work life balance $(75 \%)$

- Workload $(71 \%)$

- Target driven culture (57\%)

- Teaching making me ill (51\%)

- Government initiatives (43\%)

- Lack of support from management (38\%)

We also asked teachers (closed option answer) who were still in the job why they may leave in the future and the results were as follows.

- Workload (83\%)

- Improve work life balance (76\%)

- Not Feeling Valued (58\%) 
- Target driven culture (55\%)

- Government initiatives (47\%)

- Lack of support from management (47\%)

As can be seen, the reasons for actually leaving and those predicted are broadly similar, with workload and work-life balance being the most frequent responses. This is despite an awareness of workload before entering the profession as mentioned above. Our teachers knew about the workload and thought they could cope, but the reality was different.

Workload was described as 'incredible', 'unmanageable and unsustainable', 'insane' 'unrealistic' and 'extreme'. People claimed to work 11-hour days, 60-70 hours per week and 'not having weekends or evenings free during term time to pursue personal interests' (f, 3640, PGCE primary, 5 years, intends to leave). They argued that the work was constant 'could never feel as if I'd finished for the day or week', 'always took work home with me',' could never switch off'. Many detailed their workload, for example, - 'I was up at 5am every day, commuting/in school until 5pm, then working at home until at least 10pm and working at least 4 hours each weekend day' (f, 26-30, School Direct primary, 2 years, withdrew during training).

Similarly, interviews conducted for the DfE (2018: 5) concluded 'workload, government policy, and lack of support from leadership were cited as the three main reasons for leaving'. The House of Commons Report (2017:2) said 'A key driver for teachers considering leaving the profession is unmanageable workload. The Government and Ofsted must do more to encourage good practice in schools and recognise that changes to the school system and accountability play an important part in increasing workload'. Lynch et al (2016: 14) wrote; 'in our 21 interviews, workload is at the centre of why teachers are considering leaving. This is often perceived to stem from two main drivers - policy and inspection'. Lightfoot (2016) reported that of the 4450 teachers surveyed
Almost all -98\% - say they are under increasing pressure and $82 \%$ describe their workload as "unmanageable". More than three-quarters are working between 49 and 65 hours a week. Nearly three-quarters - 73\% - say their workload is having a serious impact on their physical health and $75 \%$ on their mental health. Only $12 \%$ say they have good work-life balance and only a third feel their employers consider their wellbeing.

It is interesting to recall that many of our respondents had been aware that workload was likely to be a challenge, and this didn't stop them entering the profession, so why is it so frequently cited as a reason to leave? Our data suggest it is not just the issue of the workload, and the stressful environment but the nature of the work, the accountability agenda that deprived teachers of the creativity and variety for which some had joined the profession. This is potentially linked to the notion that being in teaching stifles creativity, and it is this that leads to a person's departure. Our sample complained about the amount of planning and marking - 'the level of detailed planning and preparation and marking that was expected was simply not achievable' ( $\boldsymbol{f}, 36-40$, PGCE secondary, left after 2 years) as well as data, target and accountability pressures: 
the pressures of data - which children I need to push to make accelerated progress, which children I need to focus on to help them get a combined score in maths and English. It just takes away from the purpose of my job which is helping all the children in my class (f, 26-30, PGCE primary, 2 years, intends to leave).

lots of paperwork/data/ etc is done purely for the sake of it, feels like box ticking/jumping through hoops - not actually for the benefit of teachers or students or teaching or learning... then the next initiative is introduced and your work becomes entirely futile (f, 26-30, School Direct secondary, 1 year, intends to leave).

there is little creativity and fun in my daily job. I'm hoping that I will think differently in my new post, but I worry that all schools are just becoming so target driven that it will be difficult to find a nice place to work where I feel valued and respected ( $m, 36-40$, Teach First primary,5 years, intends to stay).

Similarly, summarising their own research into the impact of government policies on the lives of teachers, Macbeath and Galton (2008: 2) concluded 'the vocabulary of embattlement was juxtaposed with references to spontaneity, fun, creativity all as aspects of teaching that were seen to be lost with references to the love of teaching being squashed out of people'.

Accountability mechanisms can also impact on teacher self-efficacy (Guskey 1987) and lead to role-conflict (Iwanicki 1982) which also impact on retention. Teacher efficacy refers to teachers' beliefs that they can influence even the most unmotivated student to learn (Guskey 1987). According to Berryhill et al (2009: 2) 'policy analysts have found that accountability policies put teachers in a position in which they do not feel efficacious. That is, many educators do not believe they can influence student learning as demanded by accountability systems', and this in turn leads to teachers burning out. Using data from the Teaching and Learning International Survey involving 73,100 teachers in 23 countries, Vieluf et al (2013:101) found that 'teacher self-efficacy relates positively to teachers' job satisfaction and classroom teaching practices, independent of the cultural background of the teachers'. Skaalvik and Skaalvik (2010), investigating the links between teacher burnout and teacher selfefficacy surveyed 2249 Norwegian teachers in elementary and middle schools and concluded that 'job satisfaction was positively related to teacher self-efficacy and negatively related to both dimensions of teacher burnout with emotional exhaustion as the far strongest predictor... autonomy, time pressure, and teachers' relations to parents stand out as the most important school contextual variables affecting teachers' job satisfaction' ( $p$ 1066).

Role conflict refers to the situation when teachers have two roles that are incompatible, Berryhill et al (2009 p 2) giving the example of balancing quantity of material covered with quality of work. Iwanicki (1982) following a study of 469 teachers defined role conflict as 'the simultaneous occurrence of two or more sets of inconsistent expected role behaviours for an individual' ( $p$ 61) and concluded it was a significant contributor to teacher burnout.

Drawing upon existing research literature and findings from a four-year Department for Education and Skills funded project with 300 teachers in 100 schools, the VITAE project 
investigated variations in teachers' work and lives and their effects on pupils. Day et al (2006: vi-vii) found:

Teachers' sense of identity is a major contributing factor to teachers' commitment and resilience. It is neither intrinsically stable nor unstable, but can be affected positively or negatively by different degrees of tension experienced between their own educational ideals and aspirations, personal life experiences, the leadership and cultures in their schools, pupils' behaviour and relationships and the impact of external policies on their work.

In this context, Cochran-Smith, (2004: 391) concludes that teachers need 'school conditions where they are successful and supported, opportunities to work with other educators in professional communities, differentiated leadership and advancement prospects and good pay for what they do'. This can affect perceived collective self-efficacy (Skaalvik and Skaalvik 2007). Unsurprisingly, in our data, lack of support to cope with performative work demands was also an issue;

Very poor and unsupportive line management is by far the worst aspect of my job. The crippling workload is also killing me but would be a lot more manageable if I was thanked and appreciated and valued (f, 46-50, PGCE secondary, 5 years, intends to leave).

A suspicious and unsupportive SLT: The constantly shifting goalposts from SLT (alongside a big fear of Ofsted from them) - it felt 'them and us' rather than as though we were all on the same side of achieving what was best for the children ( $m, 36-40$, PGCE secondary, 5 years, left).

Existing research supports the view that schools do indeed make a difference to teacher motivation. Guarino and Santibafiez (2006: 201), in a review of the then available literature, concluded that 'schools that provided mentoring and induction programs particularly those related to collegial support had lower rates of turnover among beginning teachers. Schools that provided teachers with more autonomy and administrative support have lower levels of teacher attrition and migration'.

As one respondent said

I do not think it is the children/behaviour that drives teachers away from the profession - it is the lack of support and trust from management that ultimately is directed from the state - pressure of constant tests, assessments and targets. Teachers needed to be trusted more ( $f, 26-30$, Teach First primary, 3 years, intends to stay).

Another agreed;

Teaching is wonderful when you are trusted and you can pour all of your time into your classes and making them interesting and meaningful for your students. The current climate in England with targets and monitoring impede teachers ability to do 
this. Teachers teach precisely because they want to work with and help children.

They leave because their professional judgement is questioned and they sometimes are asked to do things which go against their integrity (m, 26-30, Teach First secondary, 2 years, working in Spain).

It is this lack of trust, within a target driven accountability culture which seems to drive the discourse of disappointment which pervades our data.

\section{Conclusion.}

Our study supports the observation of a high turnover in teaching. With $40-50 \%$ of our respondents leaving or considering leaving within 10 years of beginning teacher training, it would certainly seem that teaching is not a career for life. But what this survey reveals is that this is not through choice. On entry, teaching is still generally viewed as a long-term career by the majority of our respondents, only a small percentage seeing teacher training as a route to another career $(7 \%)$. This amplifies the problem of teacher attrition as those who want to be teachers are committed to the profession and yet, somehow, that commitment is eroded in a very short space of time. It is not as if they were not aware that teaching was going to be demanding, however they feel that the demands of the job outstrip their capacity to adapt.

Underlying this loss of commitment seems to be a contradiction between expectation and reality, the practices of being a teacher impeding the ability to be a teacher. Many of our sample thought they could cope with the workload, but lack of support and the target accountability culture seemed to be worse than they had thought and led to many leaving, and further numbers considering it. Some of our sample expressed a worry that this is unsustainable

I have so many friends and colleagues who have left teaching due to the workload, stress and general exhaustion. They have transferred to other jobs (some less well paid) and they say their quality of life has been greatly improved by leaving teaching. This needs to be addressed urgently otherwise more skilled teachers will leave the profession (f, 31-35, PGCE secondary, 5 years, intends to leave).

It is a great profession with many non-monetary rewards. I do worry however that the amount of pressure put on teachers and pupils as well as the incredibly high workload will eventually drive all good teachers away from the profession (f, 26-30, PGCE secondary, 3 years intends to stay).

This points to a discourse of disappointment that hangs over teaching, driving those who might have a significant contribution to make away from the profession. A recent report by the OECD (Schleicher 2018) highlighted teacher well-being as an issue of concern 'job satisfaction surveys applied in different countries have shown that teachers' stress resulting from their professional activities is a phenomenon to be taken seriously' ( $p$ 
91). The report summarised research suggesting that 'stressful working environments may affect teachers' motivation, self-efficacy and job commitment' ( $p$ 11). The report associates teacher well-being with the cognitive skills required to the job well (and links this to self-efficacy), and emotional and physical health. Our data paints a somewhat bleak picture of teacher well-being within a culture of accountability and performativity.

This raises the questions: what can be done to arrest this trend? The general response from government is that teaching will be improved by reducing workload (Coughlan 2018), removing unnecessary tasks and increasing pay. This may help, and our study does continue the discourse that workload is key. However, it also indicates that part of the problem lies within the culture of teaching, the constant scrutiny, the need to perform, and hyper-critical management. Reducing workload will not address these cultural issues.

Our findings illustrate the link between workload fears and the reality of working within the accountability performativity context. However, these observations must be treated with caution. The first, is the problem of retrospective understanding of motives for becoming a teacher. We do not know the extent to which they might be working within a narrative of teaching that extols the altruistic motive. Perhaps if they were asked before starting teacher training a different set of motives might be expressed. Second there is the issue of relative weighting. Asking respondents to identify their reasons for becoming or leaving teachers is a broad brush which gives equal weighting to each item. It could easily be the cases that those who highlight teaching as a stepping-stone might have also been seeking to make a difference, but we do not know the relative importance for them. Third, there is the problem of response might be limited to only those who feel they have something to say either positive or negative potentially missing a middle ground of opinion. Finally, there is the problem of knowing what is meant by high workload, is this work that cannot be completed in the allotted time or work that is seen as irrelevant and reducing the time available for important tasks? It is these issues that we hope further research will resolve.

\section{References}

Allen, R., Burgess, S. and Mayo, J. (2017) The teacher labour market, teacher turnover and disadvantaged schools: new evidence for England, Education Economics, 26 (1), 1-20.

Ball, S. (2003) The teacher's soul and the terrors of performativity, Journal of Education Policy, 18(2), 215-288.

Ball, S.J. (2008) The Education Debate (Bristol, Policy Press).

Breslin, T. (2002) Chasing the wrong dream; the quest for teacher professionalism in the age of the citizenship school. In M. Johnson and J. Hallgarten (Eds.) From Victims of Change to Agents of Change: The Future of the Teaching Profession (London, IPPR), 194219.

Burghes, D., Howson, J., Marenbon., J; O'Leary J., Woodhead, C (2009) Teachers Matter: Recruitment, Employment and Retention at Home and Abroad. The Report of the Politeia Education Commission, (London, Politeia). 
Cacha, F. B. (1981) Teacher burnout: causes and solutions, Kappa Delta Pi Record, 18 (1), 26-27.

Cater, J. (2017) Wither Teacher Education and Training (Oxford, Higher Education Policy Institute).

Cochran-Smith, M. (2004) Editorial. Stayers, leavers, lovers and dreamers: insights about teacher retention, Journal of Teacher Education, 55 (5), 387-392.

Coughlan, S. (2008) Damian Hinds to Cut Workload to Tackle Teacher Shortage. Available at:

http://www.bbc.co.uk/news/education-43345857 (accessed 24 March 2018)

Cuddapah, J. L., Beaty-O'Ferrall, M. E., Masci, F. J. and Hetrick, M. (2011) Exploring why career changers leave teaching, The New Educator, 7(2), 114-130.

Day, C., Kington, A., Stobart, G. and Sammons, P. (2006) The personal and professional selves of teachers: stable and unstable identities, British Educational Research Journal, 32(4), 601-616

den Brok, P., Wubbels. and van Tartwijk, J. (2017) Exploring beginning teachers' attrition in the Netherlands, Teachers and Teaching: theory and practice. 23 (8), 881-895.

DfE [Department for Education] (2018) Factors Affecting Teacher Retention: qualitative investigation research report. Available at:

https://www.gov.uk/government/publications/factors-affecting-teacher-retention-qualitativeinvestigation (accessed 1 March 2018)

Ewing R. and Smith D. (2003) Retaining quality early careers teachers in the profession, English Teaching Practice and Technique 2(1), 15-32.

Farinde, A. A., Allen, A. and Lewis, C. W. (2016) Retaining black teachers: An examination of black female teachers' intentions to remain in K-12 classrooms, Equity \& Excellence in Education, 49(1), 115-127.

Goldacre, M. J. and Lambert, T. W. (2013) Participation in medicine by graduates of medical schools in the United Kingdom up to 25 years post-graduation: national cohort surveys, Academic Medicine, 88(5), 699-709.

Grayson, J. and Alvarez, H. (2008) School climate factors relating to teacher burnout: A mediator model, Teaching and Teacher Education, 24(5), 1349-1363.

GTCE, General Teaching Council for England (2002), Teachers on Teaching: a survey of the Teaching Profession (London, GTCE).

Guarino, C. and Santibafiez, L. (2006) Teacher recruitment and retention: A review of the recent empirical literature, Review of Educational Research, 76(2), 173-208. 


\section{Guskey, T. R. (1987) Context variables that affect measures of teacher efficacy, Journal of Educational Research, 81 (1), 41-47.}

House of Commons Education Committee (2017) Recruitment and Retention of Teachers (London, House of Commons).

Ingersoll, R. M. (2002) The teacher shortage: A case of wrong diagnosis and wrong prescription, NASSP Bulletin, 86 (631), 16-30.

Ingersoll, R, Merrill, L and Henry M (2016) Do accountability policies push teachers out? The Working Lives of Educators 73 (8): 44-49

\section{Iwanicki, E.F. (1982) Perceived role conflict, role ambiguity and teacher burnout, Educational Administration Quarterly, 18(1), 60-74.}

Joseph, P. B.and Green, N. (1986) Perspectives on reasons for becoming teachers, Journal of Teacher Education, 37(6), 28-33.

Karsentil,T. and Collin, S. (2013) Why are new teachers leaving the profession? Results of a Canada-wide survey, Education 3 (3), 141-149.

Kyriacou, C. (1987) Teacher stress and burnout: an international review, Educational Research, 29(2), 146-152.

Lightfoot, L (2016) Nearly half of England's teachers plan to leave in next five years, The Guardian, 22 March. Available at:

https://www.theguardian.com/education/2016/mar/22/teachers-plan-leave-five-years-surveyworkload-england (accessed on 28 November 2017)

Lindqvist P., Nordanger, U.K. and Carlsson, R. (2014) Teacher attrition the first five years a multifaceted image, Teaching and Teacher Education, 40 (1), 94-103.

Lynch, S., Worth, J., Bamford, S. and Wespieser, K. (2016) Engaging Teachers: NFER analysis of teacher retention (Slough, NFER).

MacBeath, J., Galton,M., with Steward, S. and Page, C. (2008) Pressure and professionalism; the impact of recent and present government policies on the working lives of teachers (Cambridge Faculty of Education, NUT)

Makela, K., Hirvensalo, M. and Whipp, P. R. (2014) Should I stay or should I go? Physical education teachers' career intentions, Research Quarterly for Exercise and Sport, 85(2), 234-244.

Marsh, S (2015) Five top reasons people become teachers - and why they quit. Available at: https://www.theguardian.com/teacher-network/2015/jan/27/five-top-reasons-teachers-joinand-quit (accessed 28 November 2017) 
Nieto, S. (2003) What Keeps Teachers Going? (New York, Teachers College Press).

Nulty, D. D. (2008) The adequacy of response rates to online and paper surveys: what can be done? Assessment \& Evaluation in Higher Education, 33(3), 301-314.

Perryman, J (2009) Inspection and the fabrication of professional and performative processes. Journal of Education Policy 24(5), 609-629

Pohar, M., Blas, M. and Turk, S. (2004). Comparison of logistic regression and linear discriminant analysis: a simulation study, Metodoloski Zvezki, 1(1), 143-161.

Poppleton, P. and Williamson, J. (Eds.) (2004) New Realities of Secondary Teachers' Work Lives (London, Symposium).

Reed, P.and Wu, Y. (2013) Logistic regression for risk factor modelling in stuttering research. Journal of Fluency Disorders, 38(2), 88-101.

Richardson, P. W. and Watt, H. M. G. (2005) 'I've decided to become a teacher': Influences on career change, Teaching and Teacher Education, 21(5), 475-4.

Savage, M (2017) Almost a quarter of teachers who have qualified since 2011 have left profession. Available at: https://www.theguardian.com/education/2017/jul/08/almost-aquarter-of-teachers-who-have-qualified-since-2011-have-left-profession (accessed 28 November 2017)

Schleicher, A (2018) Valuing our teachers and raising their status: How communities can help, (Paris, OECD Publishing).

Sims, S. and Allen R. (2018) Identifying schools with high usage and high loss of newly qualified teachers, National Institute Economic Review, 243 (1), R27-R36.

Sinclair C. (2008) Initial and changing student teacher motivation and commitment to teaching, Asia-Pacific Journal of Teacher Education, 36(2), 79-104.

Skaalvik, E.M. and Skaalvik, S. (2010). Teacher self-efficacy and teacher burnout: A study of relations, Teaching and Teacher Education, 26 (4), 1059-1069.

Surman, G., Goldacre, M. J. and Lambert, T. W. (2017) UK-trained junior doctors' intentions to work in UK medicine: questionnaire surveys, three years after graduation, Journal of the Royal Society of Medicine, 110 (12), 493-500.

Stoel, C. F. and Thant, T.-S. (2002) Teachers' Professional Lives - a view from nine industrialized countries (Washington, DC, Milken Family Foundation).

Watt, H. M. G., Richardson, P. W., Klusmann, U., Kunter, M., Beyer, B., Trautwein, U.and Baumert, J. (2012) Motivations for choosing teaching as a career: An international comparison using the FIT-Choice scale, Teaching and Teacher Education, 28(6), 791-805. 
Williams, Y (2017) Rather than asking why teachers leave the profession, we should wonder that they remain Times Education Supplement 2 May. Available at:

https://www.tes.com/news/school-news/breaking-views/rather-asking-why-teachers-leaveprofession-we-should-wonder-they (accessed 28 November 2017) 